\title{
Maciej Gladyga
}

mgr inż.

Zastępca Dyrektora

Ministerstwo Infrastruktury i Budownictwa, Departament Kolejnictwa

DOI: 10.35117/A_ENG_16_05_07

\section{Selected issues related to building investment portfolio and preparing projects}

\begin{abstract}
This paper deals with selected aspects of project portfolio development with the view of investment interaction within and outside a given organization. Having in mind the wide scope of the topic, the focus is put on relations among the projects as elements of the system. The possibility of synergy or competition effect among them is pointed out. As regards the investment preparation topic, the issue of consultation, as a key step of prerealization phase, is discussed.
\end{abstract}

Keywords: Investment Portfolio; Project

\section{Relations between projects in the process of building investment portfolio}

People with no experience in investment management may seem that building a portfolio of investment projects in infrastructure modernization is a task to a certain reconstructive degree. A superficial approach to the subject suggests that it is only to provide a simple sum of the investment plans of the entity. This understanding is fundamentally incorrect, but unfortunately quite common. Narrow looking at the issue of investment planning can have a very negative impact on many areas inside and outside the organization. There is no need to convince anyone that in case of the railway sector and the investments carried out by the national infrastructure manager, the latter aspect - here defined, among other things as the impact on the possibility of railway traffic as the least disturbed, or the condition of the market executive - is far more important than the perturbations in PKP PLK SA.

The first point is to formulate the basic question: what is the justification for strategic and operational planning. The answer may be trivial to some, but according to the author it is worth to realize - success in the implementation of the investment should not be based on luck and positive coincidence. If we add to this the proper planning and broad definitions, containing an element of risk assessment review of resources and environmental analysis, scenarios and variants, we can talk about the solid foundation of development.

It is worth noting that for building investment portfolios can be effectively used a systems approach. If you accept the basic definition of the system as a set of elements with links between them and with the environment, it is easy to see the parallels with the project portfolio. It is therefore determined not only as a set of investment projects, but also through the interaction of individual projects and the impact on the environment. Coupling between projects in the modernization of the infrastructure can be illustrated in many ways.

First of all, in connection with the need to keep moving well during the works, it is necessary to assess whether the capacity of the modernized line will be reduced enough to firmly been disrupted movement of trains. In extreme situations, we have to deal with a break in traffic throughout the period of investment, particularly in the case of single-track line. If there is this situation it is necessary to investigate the possibility of construction of alternative routes. At this point, there is the potential issue of the relationship between the projects in the portfolio of investments, because it may be that at the same time has been tentatively scheduled work on the touring. Awareness of this fact makes it possible to change schedules or ranges of tasks at an early stage before they are advanced preparatory work and 
administrative procedures so that the negative effects were offset by the movement of trains. Unfortunately, in practice co-ordination in this field very limp, especially in large organizations where for the conduct of investment is responsible number of cells in the assigned territory. Existing specialized resources is therefore important in organization to integrate the knowledge and enterprise-wide plans.

Another example of the interaction of projects is the potential impact of one of them for economic reasons or anothers' technical parameters. Observations investments made in recent years on Polish tracks, in particular those that are co-financed from EU funds, allow you to place a bold thesis that this aspect very little or not at all taken into consideration. The effects of individual projects can be strengthened on the basis of synergy, but there is also the possibility of potentially competitive relationship.

For example, the combination of two points on the network, supported in parallel by two nearby countries from each other railway lines of similar length routes, there is a heavy load in freight and passenger transport (long-distance, regional and agglomeration), and it is necessary to carry out the investment with a very limited budget . The use of effect of synergy may allow to save money and to improve the conditions of traffic in connection with its separation. If we look at the two lines together, on the one hand, it is necessary to provide for freight transport opportunities for long trains and high parameters permissible pressure of axle, on the other hand for passenger trains must be taken to ensure a high maximum speed, and the system station, which will allow overtaking slower regional trains and agglomeration by faster long-distance. Of course, it would be optimal for every part of the network in the country was at least double-track, electrified, with a maximum pressure of 22.5 tonnes per axle without speed limits, allowing trains with a length of 750 meters and stations every few kilometers, allowing overtaking and crossing, but to focus should be on the realities, in particular economy in expending limited resources.

In such a situation you can approach to two lines as one of a multiple and treat the sum of the parameters as a whole, focusing on providing on each of the strings of parameters appropriate for other traffic. This will allow e.g. save funds related to improving the line speed of a trademark (straightening curves, elimination of level crossings, etc.). On the other hand, you can optimize the scope of the investment on the line passenger e.g. with regard to the need to strengthen the construction of engineering facilities, the reconstruction of the station for the longest warehouses.

Perhaps for some, such putting the matter is controversial in principle, that if we invest, we should always provide the best available solution, but it should be emphasized once again that the resource investment resources are finite and must not ignore this fact.

At this point you can smoothly switch to a negative relationship in terms of economic justification projects, in contrast to the above described effect of synergy. If we realize that in assessing the economic viability of the projects are discounted revenues and costs in the very long term, the issue of investment costs, future maintenance costs of infrastructure, but also income from sharing and in this context, the possibility of generating growth in transport, becomes crucial. In case of limited opportunities to generate additional streams of cargo or passenger in the same to the one described previously for the two lines, taking into account future maintenance costs should be considered at the construction of the investments portfolio whether the solution to the situation is not focusing on one string and equipping it with the parameters for both types of traffic. It may turn out that the implementation of two projects with limited ranges (not to mention full) reaches a total of worse economic indicators, i.e. the economic internal rate of return than the full modernization of the line with regard to the analysis of lower maintenance costs and revenues of the second line, which will remain in the non-investment option. 
In summary, in addition to the study of objective selection criteria of investment, such as traffic, location in relation to the traffic generators, growth parameters as a result of the project in relation to the status quo, etc., extremely important is study the relationship between the individual projects in the plan. While it may be observed that the interactions with the environment in a natural way are within the analysis (e.g. The analysis of the availability of other modes of transport on a particular route or zone), interfere of investments within the same investment portfolio is marginalized.

\section{Consultation as a key element of the preparatory process - the basis for successful investment}

One of the most important stages of investment planning, both at the conceptual stage, and as clarifying the scope in the course of administrative proceedings and design, are public consultations. Failure to act in this area in the vast majority of cases are fateful and repeatedly lead to delays or even block the entire project. There is a tendency to limit the investor or representing him the person responsible for the process of preparing and obtaining the required decisions, only to the minimum pursuant to the provisions of the consultation. The reasons for this procedure is at least a few, and often we have to deal with the situation when in one case they occur together.

Firstly, conducting extensive consultation requires thought-out strategy and develop a detailed plan. We cannot talk about the correct approach to the problem, if at the beginning there will not be properly defined circle of parties interested in the project and the community. It is therefore necessary to devote adequate time to examine what could be a potential range of influence of our intentions. It is worth noting that the impact it can have a very different character, and can occur at different stages of the investment, from preparing to enter a period of functionality.

For example, completely different is the impact of a major infrastructure project for the residents of the locality in which it is located, during the works and after their completion. In the vast majority of cases, the period in which the works are associated with inconveniences for the people living in the vicinity of construction sites, warehouses materials, or along the access roads to them, among which move usually heavy equipment. This gives a rise to social discontent, which if will be not properly taken seriously by the investor and its contractors, may escalate to levels difficult to arrange and consequently protests and claims. At the same time after the completion of the implementation phase, as a rule should be followed by a significant improvement in living conditions, also compared the pre-investment, e.g. noise reduction as a result of road repairs on a railroad crossing. Unfortunately, practice shows that it does not always thake place and there are groups that have a sense that despite the patient endurance inconvenience during the works, when put into use does not feel any improvement, and sometimes complain about the deterioration of the living conditions and opportunities business. There is no doubt that there is no possibility of reconciling, often contradictory and conflicting, interests, but a thorough analysis of a number of such cases indicates that it was possible to avoid embarrassing situations, if proper carried out was consulted.

The consultation process requires a dedication of time and resources, and if you approach it in purely financial categories in isolation from social issues and hardly measurable risk in this regard it is for the investor and the contractor's expense, in exchange for which no effect is obtained expressed in kilometers, tonnes the arts.

Proper identification of the public consultation target groups can be done on the basis of a simple tool to systematize their essential characteristics and circumstances of the project. The following proposed approach to this issue, which should be emphasized that this is merely an example, which should always be adapted to the specific conditions in which an 
investment is carried out. In this task there is no rigid rules, and it must be based on experience and understanding of the specific case.

The first point is to define the phase of the project, which is clearly different potential impact. In each phase, it is necessary to define the stakeholders and definition of their nature (local governments, individuals, business entities, including the identification of their size, business profile, positioning in the local market, etc.), which affects e.g .: on the forms of contact, strength in negotiations, interest in the topic, etc. It is also necessary, as mentioned above, to examine whether a group is as interested in an investment only for the duration of one of the phases, and also appears in the other, and what essential if changes nature of the relationship with the investor or the approach to the project. Very important is also the estimation of the strength of the group or entity to both the investor and the contractor, as well as to the environment. To illustrate, it can be indicated that as long as a matter of law a group of residents has no role in the relationship between the authorities, the contractor and subcontractors, because these involve only the rules and contractual provisions, it is not difficult to recall numerous examples, when social discontent leads to delaying or even blocking the investment.

It is therefore tempting to draw up a statement, in which will be included all the relationships with the environment and the possible ways of influence on them, so as not to lead to a situation where it will be necessary to take corrective action at an advanced stage of the project. It is obvious that such activities are generally more difficult, more expensive and often do not bring the expected results.

Experience shows that the proper definition of entities interested in the project and get to know their demands allow, for example, to propose equivalent of the station point of view solutions, which while avoiding attempts to torpedo investments at the state of obtaining administrative decisions. You can ironically and metaphorically say that the biggest opponent of the project from the very beginning should be its chief consultant.

Finally, we put the thesis addressed to professionals in the rail industry, it may sound controversial, and for some it will be assessed as a sign of arrogance. Unfortunately, if you look at the side of the process of building investment portfolios and preparing investments, including ways of consultation, you can multiply examples of approaches pointing to lose sight of the fundamental role of the railway infrastructure. The essence of it is yet to provide optimal conditions for the transport of persons and goods. At the same time the range of investments and how they perform over time makes the impression that they are carried out in complete isolation from the social and economic needs, and figuratively speaking, they reflect (here comes heard statement) 'attention to the comfort of railwaymen, rather than anything else". These words are also the same accurate and up to date for all institutions having an impact on investment planning. It is the author's opinion, to move away from the paradigm of the uniformity of solutions for railway infrastructure investment for a flexible approach to adapt to different environment projects. 